\title{
Psychosocial Problems in Women with Gynaecological Cancer - A Cross Sectional Survey
}

\author{
Ajitha Kumari T Y \\ MSc Obstetric \& Gynaecological Nursing, Lecturer, CON, AFMC
}

\begin{abstract}
Background: Modern cancer treatments can cure or prolong patients' lives. However, the associated physical and psychosocial problems can detrimentally affect patients' compliance with treatment and ultimately their outcomes. When much of the attention has been focused on the physiological care of gynecological cancer survivors, the consequences of cancer and its treatments, psychosocial wellbeing and quality of life remain relatively underexplored. Therefore, nurses need to recognize the problems experienced by these patients and help resolve these problems. Objective: The aim of this study was to assess and categorize the psychosocial problems as per their severity in gynaecological cancer survivors of a teritiary care hospital and determine their association with the selected variables. Methods: A cross-sectional survey was conducted on a total of 80 hospitalized women with gynaecological cancers who underwent treatment in the oncology unit. The psychosocial problems perceived by women were assessed and categorized according to their severity, using a structured interview questionnaire- Psycho-Social Assessment Questionnaire (PSA). Results: Mean age of women with gynaecological cancers who participated in the study was 55years with most of them in the advanced stage of cancer undergoing various treatment modalities. Majority of them (96.2\%) experienced moderate to severe psychosocial problems across various domains. Relatively higher proportion (30.07\%) of psychosocial problems was constituted by psychological issues followed by those of family and social domains while financial problems had the least contribution. Moreover moderate and severe psychosocial problems were also observed in the areas of psychological, family and social and informational domains. This study also indicated that among the top ten priority problems, four were from the psychological domain and three each from informational, and family \& social domain. Fear of spread and recurrence of cancer, feelings about the changes in physical appearance, difficulty in communicating problems to family members and not informed about diagnosis and prognosis by healthcare staff are the top four psychosocial problems experienced by the participants. Age, stage of cancer, duration of cancer diagnosis, type of treatment received showed highly significant association with psychosocial problems at $p<0.05$. Conclusions: This study served to highlight the psychosocial problems and begs comprehensive assessment and extended psychosocial services to address the issues of gynaecological cancer survivors to meet their ongoing needs in order to improve long term psychosocial outcomes and Quality of life. Implications for Practice: This study indicated that there are specific psychosocial problem areas which should be identified and assisted by effective communication and interactional nursing skills. This may provide guidance to nurses working with these women in terms of what factors to evaluate when screening patients to determine who needs psychosocial interventions at an early period. A standardized approach or tool to screen all patients attending gynaecological cancer clinic for supportive psychosocial needs could be developed. This facilitates triaging and timely referral to appropriate services.
\end{abstract}

Keywords: Psychosocial problems, supportive care needs, Gynaecological cancer, domains

\section{Introduction}

It is heart breaking to be diagnosed with cancer as it changes life profoundly and is akin to a death sentence with unknown cause, uncertain cure and sheer devastation. The issues that confront a cancer patient cuts across religion, culture, demographics and all other factors. It is predicted that in India the burden of gynaecological cancer will go up from $15.3 \%$ in 2010 to $18.3 \%$ in 2020 which are relatively mainly due to cancer to cervix, breast, corpus uteri \& ovary. ${ }^{1}$ Cancer often places a heavy burden on the survivors due to the physical distress caused by the disease and its treatment Although treatment has the potential to cure some cancers and extend lives; these regimens certainly come with a range of physical side-effects, emotional distress, psychological difficulty, and spiritual suffering. Gynaecological cancer cause disturbances to body image, feelings of helplessness, dependency, shame, guilt, vulnerability, loss of feminity \& motherhood and sexual difficulties. ${ }^{2}$ Every woman with gynaecological cancer constantly grapple with intense feelings ranging from loneliness to isolation, anxiety to suicidal ideations; hopelessness and depression; and distorted family relations to interruption in their societal relationships. Though advances in treatment of gynaecological cancers are currently improving and survival rates are steadily increasing, ill effects of cancer and its treatment can occur many years even after the treatment ends. Few studies have documented that approximately one third of all oncology patients will experience significant levels of distress which warrants psychosocial treatment. ${ }^{3}$ Though the associated physical and psychosocial problems can detrimentally affect patients' compliance with treatment and ultimately their outcomes, surprisingly much of the attention is been focused only on the physiological care of gynecological cancer survivors, the consequences of cancer and its treatments, and the psychosocial wellbeing and quality of life always remain relatively underexplored. Thus people diagnosed with cancer and their families must not only live with and manage the challenges posed to their physical health, but also need to overcome the psychosocial obstacles that interfere with their holistic health.

With the substantial number of gynaecological cancer survivors in India it is pertinent that these women be assessed for their supportive care needs especially the unmet psychosocial needs. Unlike the physical effects, psychosocial discomfort cannot be ascertained empirically and hence needs to be explored based on self-report by patients who perceive them as a problem. Problems of psychosocial nature need to be looked into with equal importance and priority, as the failure to address patients psychosocial needs can result in needless patient and 


\section{International Journal of Science and Research (IJSR) \\ ISSN (Online): 2319-7064 \\ Index Copernicus Value (2013): 6.14 | Impact Factor (2015): 6.391}

family suffering. The goal of this study is to understand the psychosocial problems experienced by women with gynaecological cancer which help nurses, who are in a unique position to monitor psychosocial distress and coping throughout their cancer journey and help them become better human beings in order to start a new life surviving with cancer. In the face of these array of potential losses what support can a health team offer to patients and their families on a day to day basis?

\section{Objective}

The aims of this study was to identify and categorize the psychosocial problems of gynaecological cancer survivors in a teritiary care hospital and determine their association with the selected variables-age, monthly income, type of cancer, stage of cancer, duration of disease, treatment modalities \&duration of hospitalization.

\section{Materials \& Methods}

A cross-sectional survey was conducted (2013) on a purposively sampled 80 hospitalized women with gynaecological cancers who underwent treatment in the female oncology unit of a teritiary care hospital in Pune after ethical clearance from the Institution and verbal informed consent from the study subjects. Betty Neumann's System model was adopted as the conceptual framework for the study. Gynaecological cancer women with varying type, duration, stage of cancer, of age above 30 years, with more than 3 days of present hospital stay undergoing various treatment modalities were included in the study. Women with previously documented psychiatric illnesses, other morbidities and poor general condition were excluded from the study. A structured interview questionnaire-Psycho-Social Assessment Questionnaire (PSA) developed and validated by experts in the field was used as a tool to assess the psychosocial problems perceived by women and the severity of problems were categorized as mild, moderate, severe using scores rated on a Likert scale. Pilot study was conducted on $10 \%$ of the total sample. The problems were assessed under various domains namely Psychological, Everyday living, family and social, financial and Informational. The women who had the mean score greater than fifty percent of the total score for each domain was considered to have moderate and severe problems. The top ten psychosocial problems in the order of priority were identified as per the items for which majority of the women had responded 3 and 4 on the Likert scale. Mean scores and percentages were calculated for categorization into mild, moderate and severe. Association of psychosocial problems with demographic and clinical variables was analyzed by ANOVA and Mann Whitney $U$ test using SPSS-16 software.

\section{Results}

Majority of the women with gynaecological cancers who participated in the study were in the age group of 45-65 years with a mean age of 55years. Majority of the women $(97.5 \%)$ were unemployed and were homemakers owing to their illiteracy, lower educational status, cultural influences, male dominance and their restricted role as mere caretakers and home makers..Majority of the women were part of extended and joint family, married and most of them stayed with their spouses who were the main source of support. Many women expressed that they were embarrassed to report many of their problems hence were undetected. Women presented with mainly two types of gynaecological cancers (Cancer ovary and cervix) and they were distributed almost equally in both the category. Participants had a mean hospital stay of 24 days owing to the distressing symptoms experienced by these women. Majority of them (96.2\%) experienced moderate to severe psychosocial problems across various domains. The mean score of psychosocial problems in the five domains indicated that psychological problems ranked the highest (30.07\%) in comparison to other four domains which were also reflected in the relative proportion. Relatively higher proportion (30.07\%) of psychosocial problems was constituted by psychological issues followed by those of family and social domains while financial problems had the least contribution (Figure 1)

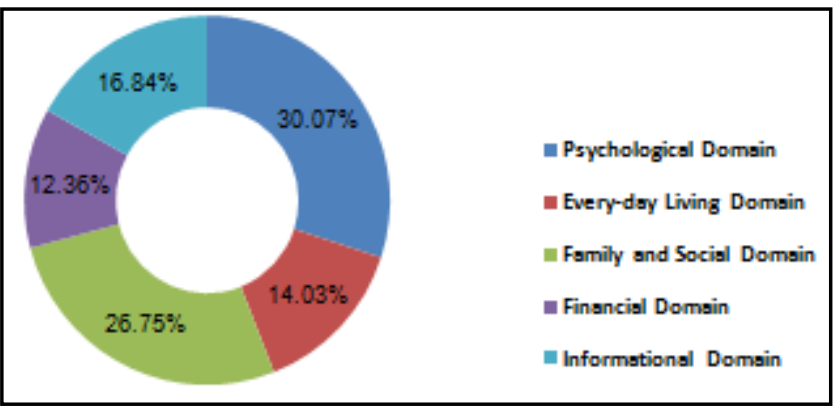

Figure 1: Relative proportions of Psychosocial Problems under five Domains

Moreover moderate and severe psychosocial problems were also observed in the areas of psychological, family and social and informational domains. (Figure 2)

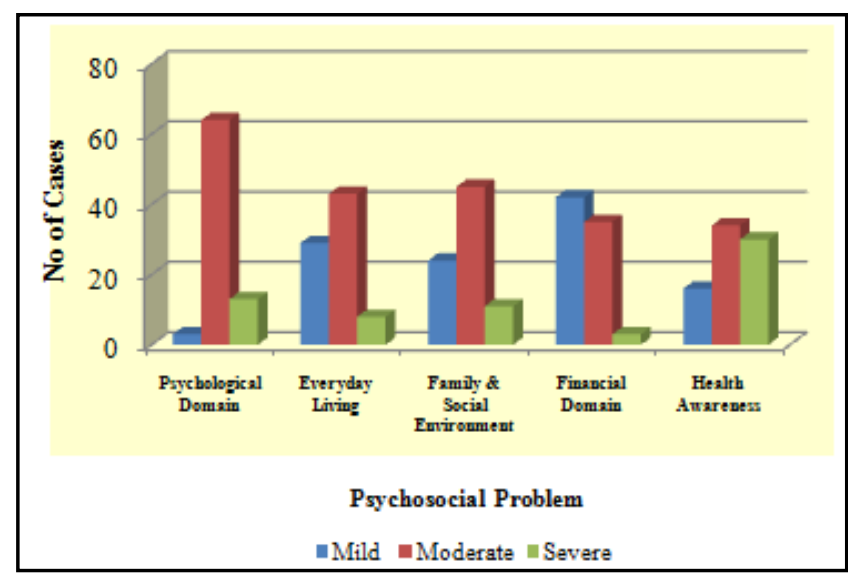

Figure 2: Psychosocial Problems as per Severity

This study also indicated that the psychosocial problems as per priority which include fear of cancer spread and recurrence, feelings of change of body image, finding difficulty in communicating problems with those closest to them, not informed about diagnosis and prognosis, worry about results of test and treatment, feeling that children \& others are not receiving care, lack of awareness about self- 


\section{International Journal of Science and Research (IJSR) \\ ISSN (Online): 2319-7064 \\ Index Copernicus Value (2013): 6.14 | Impact Factor (2015): 6.391}

care, change in feelings of intimacy and closeness with husband, and worry about illness and its outcome (Table-

1)

Table 1: Top ten Psychosocial problems among the five domains

\begin{tabular}{|c|c|c|c|}
\hline S. No. & Psychosocial Problem & Domain & No of Cases (\%) \\
\hline 1 & Fearful about spread and recurrence of cancer. & Psychological & $67(83.7)$ \\
\hline 2 & $\begin{array}{c}\text { Feeling that illness has caused changes in the way they look \& have lost } \\
\text { interest in their appearance. }\end{array}$ & Psychological & $62(77.4)$ \\
\hline 3 & $\begin{array}{c}\text { Finding difficulty in communicating problems with those closest to them } \\
\text { (Partner, children, parents) }\end{array}$ & Family \& social & $58(72.5)$ \\
\hline 4 & Not informed about diagnosis and prognosis by health care staff & Informational & $53(66.2)$ \\
\hline 5 & Feeling sad, depressed, losing interest in things, and feeling hopeless. & Psychological & $52(66.3)$ \\
\hline 6 & Worried about test results \& of treatment i.e. whether successful or not. & Informational & $48(60)$ \\
\hline 8 & $\begin{array}{c}\text { Partner, children, parents who are close to me find difficulty with the } \\
\text { support and care available them. }\end{array}$ & Family \& social & $46(57.5)$ \\
\hline 9 & Adequate information regarding how to care for self is not given. & Informational & $42(52.4)$ \\
\hline 10 & Illness has caused changes in feelings of intimacy and closeness with \\
husband. & Family \& social & $42(52.4)$ \\
\hline
\end{tabular}

Age, stage of cancer, duration of cancer diagnosis and treatment modality showed statistically significant association with psychosocial problems at $\mathrm{p}<0.05$. (Figure $3,4,5,6)$

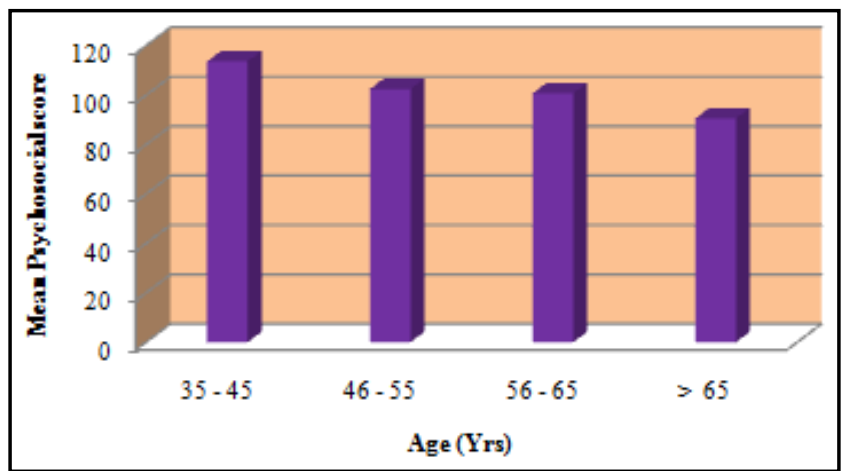

Figure 3: Association of Psychosocial problems and Age

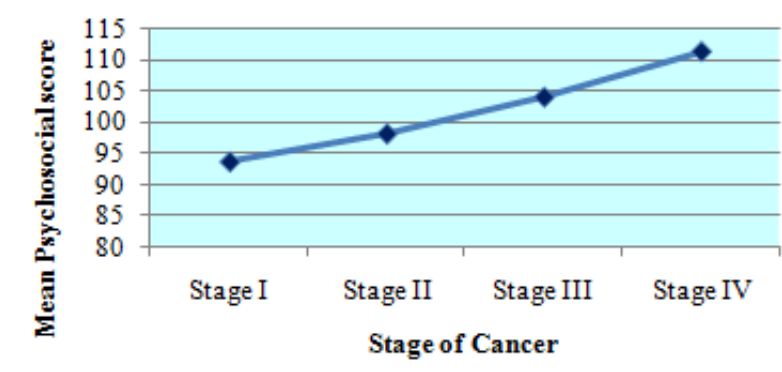

Figure 4: Association of Psychosocial problems and Stage of cancer

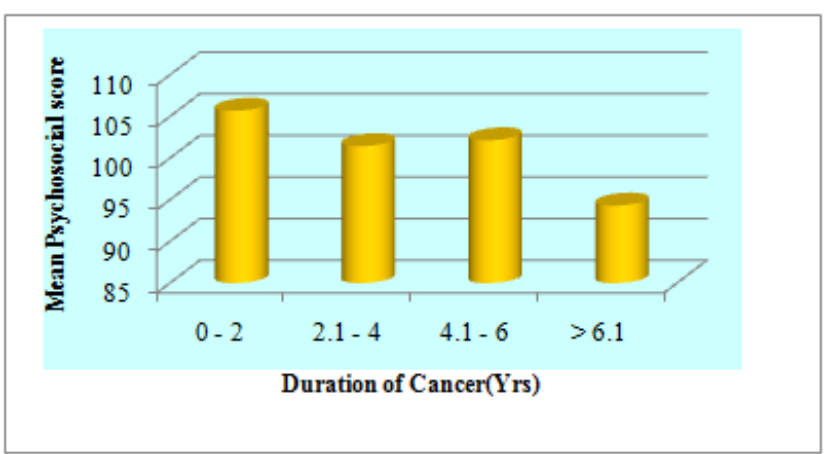

Figure 5: Association of Psychosocial problems and Duration of Cancer

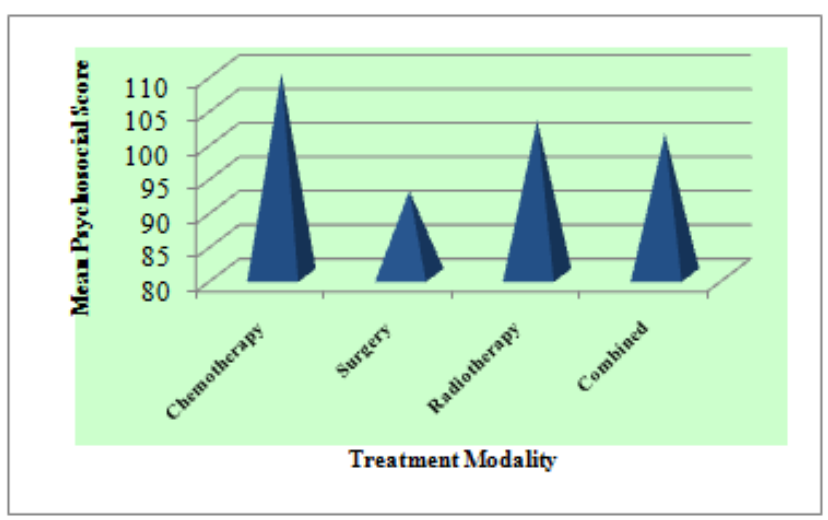

Figure 6: Association of Psychosocial problems and Treatment modalities

\section{Discussion}

The disease and treatment of cancer may lead to functional restrictions or disabilities which in turn may give rise to a diversity of psychosocial problems. These problems not being addressed can have an impact on cancer patient's recovery and long term chances of survival. The current study represents a cross sectional descriptive view of the perceived psychosocial problems of hospitalized women with gynaecological cancer undergoing treatment, across a comprehensive range of psychosocial domains (Psychological, family \& social, financial, informational 


\section{International Journal of Science and Research (IJSR) \\ ISSN (Online): 2319-7064}

Index Copernicus Value (2013): 6.14 | Impact Factor (2015): 6.391

\&, everyday living). The mean score of psychosocial problems in the five domains indicated that psychological problems ranked the highest (30.07\%) in comparison to other four domains. The prevalence of moderate to severe psychosocial problems in this study was $85 \%$ which was similar to the findings of a previous study ${ }^{3}$ but comparatively lesser than (95\%) in a separate study. ${ }^{4}$ The top ten priority psychosocial problems identified in the present study ranged between $50-83.7 \%$ which was similar to another study $(41.2-82.4 \%)^{3}$ but much higher than various other studies. ${ }^{5,6,7,8}$ This can be attributed to the individual differences, heterogeneous sample with varying demographic and disease characteristics. About 96.2\% of the patients reported moderate to severe problems in psychological domain and another $80 \%$ had problems in relation to the informational (Health awareness) domain. Few other studies reported the same to be $40 \%$ in both the areas. $^{9,10,11,12}$.The severity of psychosocial problems had statistically significant association with age, 2, 13, 14, advanced stages of illness, ${ }^{14,15,16}$ duration of cancer, ${ }^{14,7 \text {, }}$ ${ }^{17}$ and type of treatment received ${ }^{18,17,11,19,20}$ which was in accordance with several other studies.

This was an Indian based study concentrating on the southern states and hence may be limited in its generalizability to other states. Small sample size and exclusion of patients who were too sick or unable to respond implies that the results cannot be generalized to the target population. This study had a 100 percent response rate and despite the limitations this is one of the studies which considered the prevalence of psychosocial problems and their association to certain socio demographic and clinical variables during hospitalization, cancer treatment and course of cancer among two common types of gynecological cancers.

\section{Conclusion}

The findings from this study can provide baseline information to nurses in cancer hospitals, primary health care settings \&cancer clinics to triage and respond to the patient's psychosocial issues and needs in order to address them effectively. Knowledge gained from this descriptive study may help nurses and other health care providers provide more responsive, emotionally sensitive and client oriented holistic assessment and comprehensive care for this vulnerable cancer patients. Cancer patients can be sensitized to the major problem areas for early reporting of distress, and encourage patient, use of existing supportive services. The knowledge can be better utilized in nurse run psychosocial care cancer clinics to triage, and identify the issues encountered by cancer patients and plan specific interventions. This study served to highlight the psychosocial problems and begs comprehensive assessment and extended psychosocial services to address the issues of gynaecological cancer survivors to meet their ongoing needs in order to improve long term psychosocial outcomes and Quality of life of many million cancer survivors across the globe.

\section{Recommendations}

Well-designed prospective trials and cross sectional studies on the factors causing psychosocial problems and barriers to psychosocial care may be carried out on a larger scale. The emotional impact and psychological problems faced by siblings of cancer patients and their subsequent behavior patterns can also form yet another important study.

\section{References}

[1] National Cancer Registry Programme. Consolidated report of hospital based cancer registries 2001-3.New Delhi: Indian Council of medical Research:2007

[2] Bodurka-Bevers D, Basen-Engquist K, Carmack C, Fitzgerald M, Wolf J, et al. Depression, anxiety, and quality of life in patients with epithelial ovarian cancer. GynecolOncol2000; 78:302-8.

[3] Carlson LE, Bultz BD. Benefits of psychosocial oncology care: Improved quality of life and medical cost offset. Health Qual Life Outcomes 2003;1:8-10.

[4] Mehelsen MY, Jensen AB, Zachariae B.Psychosocial problems and needs among cancer patients. UgeskrLaeger.2007 Apr 30;169(18):1682-87.

[5] Hwang SY, Park BW.The perceived care needs of breast cancer patients in Korea. Yonsei Med J2006; 47:524-33.

[6] Holzner B, Kemmler G, Kopp M, Moschen R, Schweigkofler H, Dunser $M$ et al. Quality of life in breast cancerpatients - not enough attention for long term survivors? Psychosomatics2001; 42:117-23.

[7] Park BW, Hwang SK. Unmet needs of Breast cancer patients Relative to survival duration.YonseiMed J 2012;53(1):118-25.

[8] Akecht T, Okuyama T, Endo C, Sagawa R, Uchida M, NakaguchtT, et al. Patients perceived need and psychological distressand /or Quality of life in ambulatory breast cancer patients in Japan Psycho oncology.2012;1(20) :497- 505.

[9] BargFK, Cronholm PF, StratonJB, Kedden S, Knott $\mathrm{K}$, Grater $\mathrm{J}$ et al. Unmet psychosocial needs of Pennsylvanian with cancer.Cancer2007; 110:631-39.

[10] Janda M, EakinEG, Bailey L, Walker D, Troy K. Supportive care needs of people with brain tumors and their carers. Support Care Cancer2006; 14:1094-1103

[11] Sanson-Fisher R, Girgis A, Boyes A, Bonevski B, Burton L, Cook P.The unmet supportive care needs of patients with cancer. Cancer[serial online]2000[cited 2012 Jan13]; 88(1): 226-37.Available from: URL:http://www.newcastle.edu.au/Resources/Researc h\%20Centres/CHERP/publications

[12] Foot G, Sanson-Fisher, R. Measuring the unmet needs of people living with cancer. Cancer Forum 2001; 19:131-35.

[13] Hipkins J, Whitworth M, Tarrier N, Jayson G. Social support, anxiety and depression after chemotherapy for ovarian cancer: a prospective study. $\mathrm{Br} \mathrm{J}$ Health Psychol2004;9:569-81.

[14] Norton TR, Manne SL, Rubin S, Carlson J, Hernandez E, Edelson MI et al. Prevalence and predictors of psychological distress among women with ovarian cancer. J ClinOncol2004[online] Mar 1[cited 2011 


\section{International Journal of Science and Research (IJSR) \\ ISSN (Online): 2319-7064}

Index Copernicus Value (2013): 6.14 | Impact Factor (2015): 6.391

Sep20]; 22(5):919-26. Available from: URL:http://www.ncbi.nlm.nih.gov/sites/entrez?cmd=s earch\&db=pubmed\&term=Norton\%20TR[au]\&dispm $\mathrm{ax}=50$ [PubMed]

[15] DerogatisLR, Morrow GR, Fetting J, Penman D, Piasetsky S, Schmale AM, Henrichs M, Carnicke CL Jr. The prevalence of psychiatric disorders among cancer patients, JAMA.1983;249(6):751-757

[16] Timothy P.Quality of life and psychosocial adjustment in gynecologic cancer survivors.HealthQual Life Outcomes. 2003; 1: 33

[17] Girgis A, Boyes A, Sanson-Fisher RW, Burrows S. Perceived needs of women diagnosed with breast cancer: Rural versus urban location. Aust. N Z J Public Health.2000; 24: 166-73

[18] Vistad I, Fossa SD, Dahl AA. A critical review of patient-rated quality of life studies of long-term survivors of cervical cancer. Gynecol. Oncol 2006;102(3):563-72

[19] Steginga S K, Occhipinti S, Dunn J, Gardiner R A, Heathcote P, Yaxley J. The supportive care needs of men with prostate cancer. Psycho-Oncology 2001; 10(1): 66-75.

[20]Carlson M, Strang P, Bjurstrom C. Treatment modality affects long term quality of life in gynaecological cancer. Anticancer Res. 2000.Jan Feb; 20(1):12-20 